\title{
A contemplation on the Traditional Architecture of Hot-dry Climate with Emphasize on the Interaction between Living Satisfaction and Affordability. A case Study of 'Nikandish House' in Kerman, IRAN
}

\author{
Mahla Anjomshoa*, Amineh Anjomshoa \\ Departman Of Architecture, Faculty Of Art, Architecture And Urbanism, Kerman Branch, Islamic Azad university, Kerman, Iran. \\ *Corresponding author: mahla.anjomshoa98@gmail.com
}

\begin{abstract}
Housing supply has always been one of the dilemmas of different countries, which is especially more outstanding for low-income urban groups. During the recent decades we have been witnessing the construction of housing complexes for this stratum of our society just to play the role of a shelter distancing away from living satisfaction measures. This article aims at familiarization with the general principles of Persian traditional architecture. Our traditional architecture has been developed in a manner which not only provide an affordable and inexpensive living space, but would also enhance living satisfaction aspects of our life. But unfortunately, nowadays our houses have kept distanced from traditional architecture leading somewhat to living dissatisfaction. It is the duty of our architects and designers to copy the characteristics of traditional Persian houses and adapting them with the new methods of architecture, cause satisfaction for the inhabitants. As the traditional houses are somewhat affordable, observing the principles, would lead to the development of houses which lead to inhabitants' high living satisfaction and due to economic characteristics of this type of architecture, would somehow assist the dilemma of housing crisis.
\end{abstract}

\section{Keywords: Traditional architecture, hot-dry climate, living satisfaction, affordability, Nikandish House, Kerman}

Cite This Article: Mahla Anjomshoa, and Amineh Anjomshoa, "A contemplation on the Traditional Architecture of Hot-dry Climate with Emphasize on the Interaction between Living Satisfaction and Affordability. A case Study of 'Nikandish House' in Kerman, IRAN." American Journal of Civil Engineering and Architecture, vol. 6, no. 2 (2018): 63-67. doi: 10.12691/ajcea-6-2-3.

\section{Introduction}

One of the most fundamental physiological needs of the human being according to Maslow's hierarchy of needs is Housing. Human beings start to grow inside the environment of the house and the family before entering into the society and actually form a social nucleus. The more their living space assists fulfill their needs and causes tranquility for them, the human beings as members of the social body are more successful in carrying out his/her activities. In this stage, the supply of housing especially for the low-income group has always been a dilemma for world countries to access stable development. It doesn't mean to just make a shelter, but it is the type of housing which could not only be affordable, but could also provide living satisfaction inside the traditional space. We actually felt the smart environment of the traditional house which gave us affordability as well as inhabitants' satisfaction. Today, due to spontaneous population growth, difficulties of land shortage, changes in the culture and structure of families, housing complexes and apartments have mushroomed along with the urban development in such a manner that people are bound to live in high tower story causing mass housing construction with homogeneous characteristics throughout the country, often ignoring climatic features, the objective being just development of a shelter. Today's houses observing existing features, are not able to fulfill traditional Persian needs.

\section{Investigating the Background}

Housing and living have always follow economic, social, cultural and climatic conditions of each region. The essence, shortage rate, residential needs with regard to income groups and social strata are different. It goes without saying that each group seeks its own different solutions. [1] In spite of housing importance in human life, provision of proper housing for all human beings has become a dilemma in current difficulties of the society. [2] After the industrial revolution, the global process of urbanization increased substantially followed by an array of problems including housing shortage. Actually, housing as one of the real phenomena, has become the first dilemma for the human being to fight with, trying to transform the problem and find proper and thoughtful 
solutions. [3] Housing has always been globally the concern of the governments for the poor stratum of the society in such a manner that the UNO and legislative organs of the world have ratified legal acts in order to provide housings for the low-income human beings. From the approval of human rights resolution in 1445, the right to own proper housing has been enumerated as one of the important components of favorable living standards [4] the term affordability is used in different contexts in different English speaking regions. The term affordable housing has lately started to enter into discussions. The definition engulfs the theme that the household is able to pay housing cost without shouldering extra financial problems [5]. In regard to housing planning, a proper method of affordable housing emphasizes on the residential buildings, including proper facilities by using tools bearing local qualities which would lessen the difficulties of housing constructions, reduction of dependence upon others and concurrently preserving agricultural lands. [5] The topic of household's financial ability in providing housing, is based on the fact that housing costs, have a reasonable proportion with the income. In other words, housing cost has to be at a level that the household could by using the remainder of their income, could cover all other expenses such as food, clothing, transportation, medical treatment and education. This measure is considered for various income levels, method of occupation, age, type of family and the location. Housing has been the most essential and sensitive sectors of economic and social development along with food and clothing and were considered as the most original and influential factors of human being needs. Furthermore, the most effective factor in the extent of individual's satisfaction on residential location, housing and environmental conditions.

In spite of housing importance in human life, provision of proper housing for all human beings is one of the current difficulties in human societies. In fact, it is from 18 th century concurrent with the industrial revolution and invasion of job-seeking population from rural areas to the urban regions that dilemma of housing starts to appear. Many endeavors have been done to solve this problem from three centuries ago., yet $20 \%$ of world population still don not own a place to be deserved living. [2] Although human science scholars consider the supply accessible houses as the nucleus of development and labor, today, many countries suffer from housing price increase, endangerment of low-income individuals because of financial unaffordability and the low quality of rental housing especially in metropolitan areas. Lack of accessible housing creates numerous economic problems specimen of which could be observed in social disruption. It has to be confessed that provision of affordable housing falls within the complicated areas of economic science. This complexity, stems from the diversity of plans utilized for housing development. [6]

Leo, has divided satisfaction into two major sections: 1Social satisfaction which is an essential component an individual feels from the people in the circle of his life, like neighborhood units2- physical satisfaction which covers the areas related to housing architecture. Private housings cover both satisfactions while government housings only bring physical satisfaction, because of cheap and swift execution. [7]

The factor which places inexpensive housing as part of macro policies of the states is peoples' immediate need for housing. One of the controversial issues is the insoluble problem of housing which started from the $19^{\text {th }}$ century as the result of urbanization due to industrial revolution when UK, Germany, France and Russia faced with the shortage of housing. [8] Many studies have been carried out in regard to residential satisfaction several of which shall be expounded as follows:

"The concept of satisfaction is defined as a function of success rate and physical and mental satisfaction. It is a concept rising from the theory of motivation and needs in psychology which embodies all aspects and dimensions of life." [3] In their article, Rezaee and Kamalizadeh have pointed out that an aspect of life satisfaction stems from one's satisfaction from environment of living, thus architects' attention has been focused on increasing the quality of space to provide them with residential satisfaction. Household satisfaction from environmental conditions and housing characteristics are among the most important measures of residential quality in the process of housing policy assessment [9].

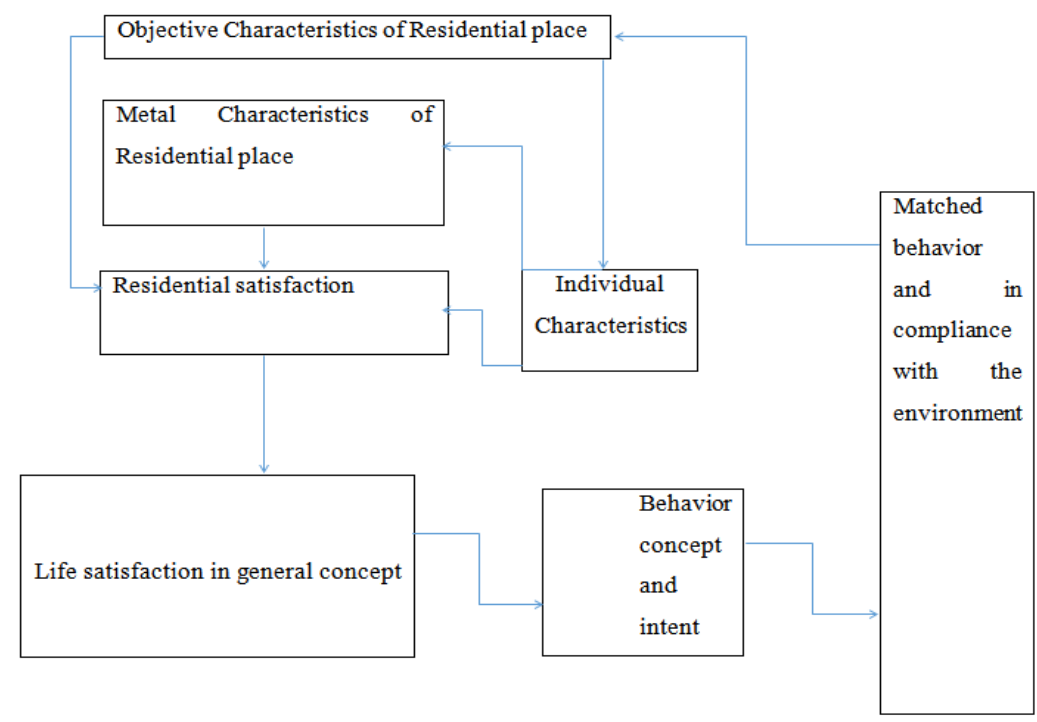

Figure 1. Amirgo model in determining residential satisfaction [12] 
Household satisfaction from residential place based on ideals, needs, and their abilities. Inequality in these three factors and the existing condition causes dissatisfaction and displacement. In these conditions, the original aim of the households from displacement is to achieve satisfaction. [10]. Residential satisfaction rate of the inhabitants is generally related to two quality factors of residential units and their location (from urban planning dimension). Amirgo has presented a conceptual model (Figure 1) in which attention has been paid to the method of individual interaction with his housing unit which is in fact a residential satisfaction model. Based on this model, the objective characteristics of residential environment has been assessed by the individual and has been turned into subjective characteristics and finally ascend to a specific degree of satisfaction. Afterwards, these mental characteristics are influenced by personal characteristics. In this stage, mental characteristics of individual are original elements which shall be compared with the real residential environment and ideal self. The result of this assessment from residential satisfaction is a positive state which directs the individual experiences towards his/her residential place causes personal behavior is directed in specified directions to interact with the environment.

Today, with the growth of population and expansion of urban areas the need to housing has become higher. With the recognition of past architecture and its matching with contemporary architecture, the need could be removed. Persian Traditional architecture used to possess characteristics based on master workmanship to develop cost-saving housing. This characteristics have been deployed in such a manner that would eventually cause inhabitants' satisfactions.

Some of the features would follow:

\section{A case study House: Nikandish Kerman}

Nik Andish history goes back to $110-150$ years ago, to Qajar era. The entrance is situated at the south side of the building. The building possesses an introvert structure, and there buildings on all four sides of the house. Originally, the house has had introver/extrovert form, but the interior section has been destructed due to earthquake and has been reconstructed.

\section{The Architectural Characteristics of Persian Traditional Houses}

\subsection{The Introvert Design and Keeping the Confines of the Houses}

In designing Iranian houses attention would have initially been paid to the introvert aspect of the houses and keeping the public and private confines of the house was highly respected in such a manner that members of the family could do their routine works with their minds at ease. They would never feel uneasy with the presence of guests or others who shall be privy to their secrets. In Nikandish House as evident from Figure 2, the design is quite introvert and all sections from entrance, rooms, kitchen etc. have all been introvert and keeping the confines. The kitchen is designed in uscha form that the lady would be able to work easily without being seen. Or the W.C. if far from the living quarter.

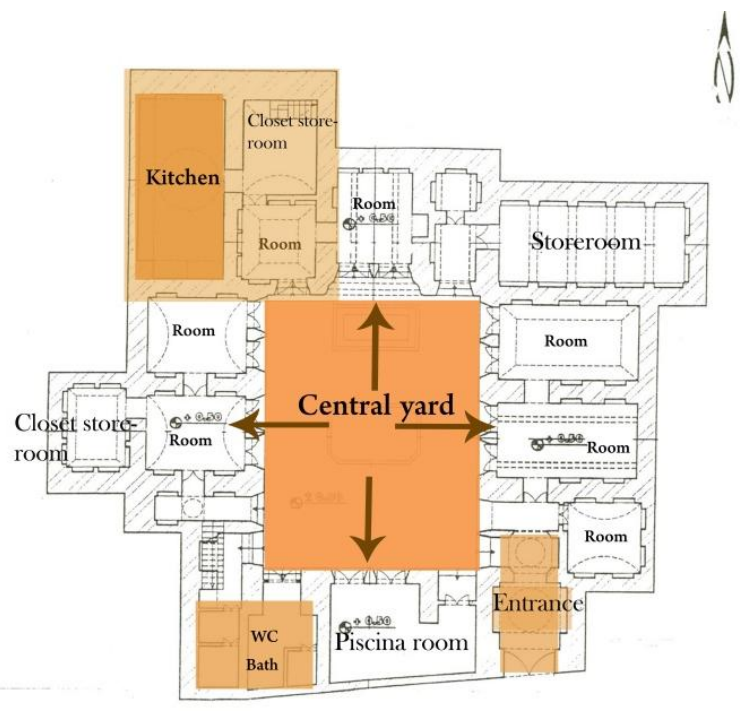

Figure 2. Different sections of Nikandish House, showing spatial confines and distances between kitchens, W.C. and rooms

\subsection{Using Local Materials}

An important factor always taken into consideration in traditional architecture has been use of local material. Utilizing local materials has been matched with the climatic condition of the region and have been cost saving in this regard. The materials utilized here are: Adobe for the whole parts along with a mortar made of clay and gypsum, bricks in the façade of the building, $25 \times 25 \mathrm{~cm}$ tile bricks as yard and roof covering and the mortar made of gypsum, clay\& straw as roof coating.

\subsection{Flexibility}

One of the important aspects of traditional Persian architecture has been the spatial flexibility of sections that matched with the inhabitants needs.

\subsubsection{Versatility}

Versatility as a kind of flexibility is one of the most essential methods to access flexibility in the architecture of Persian traditional houses. And the reason behind that is exchangeability of spatial applications during the time. Since this approach needed no vast open area or new methods, the traditional building system would be easily coordinated with the routine chores. [13]

As evident from Figure 2, some spaces are just called room not clearly specified, the reason being that these rooms could be used in proportion with inhabitants needs. For instance, one room could be used as bedroom as well as dining room. Another room could be used as guest house as well as inhabitants living room.

\subsubsection{Accommodation}

Accommodation could be used as another method of flexibility. This means adaptation of a space with new 
conditions. In Persian Traditional Houses, by using one plan, façade, and space, use could made from different days and reasons of the year. [13] Spaces titled; summer quarter, winter quarter, upstairs space, basement and roof were adapted to use in different living conditions [14].

As seen in Figure 2, it could be observed that different spaces of the house could be adapted with different seasons. As well as the roof and the basement which could change roles in different times of the year.

\subsubsection{Changeability}

As a method of flexibility to increase or decrease the quantity, partition or integration of spaces and again returning to the initial design. Could be used for adding to the spaces without increasing the area, horizontal or perpendicular expansion and dividing multi-yard houses for extended families. [13]

\subsection{Matching with the Climate}

Matching Persian traditional Houses with climatic conditions have been skilfully conducted. For example in the hottest days of the year and the hottest regions of the country, using special architectural elements would make the air temperate and even pleasant. This technic has been used through specified methods for various regions, to make the climate pleasant and to save costs. Spaces like' central yard, pond space, and wind catcher are used in this house. According to direction of sunshine, domes, arcs, small pools and fountains, small gardens are all elements for matching with the hot /dry climate of Kerman.

\subsection{Use of Module (Peymoun)}

In Persian traditional houses use has been made of module which is one of the most important points to create a general proportion in the building which would accelerate the construction speed and cost saving. According to the financial situation of the owner, there were 'large module', small module and tiny module. In the case study, module for façade, structure and decoration has been $25 \times 25 \mathrm{~cm}$ bricks for roof, $25 \times 25 \mathrm{~cm}$ bricks for yard covering and tiling.

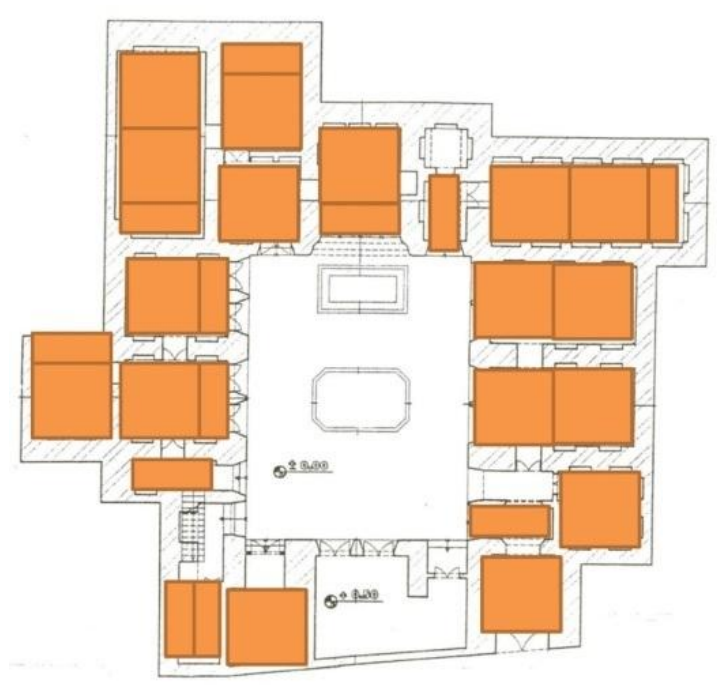

Figure 3. Using Module in Nikandish House
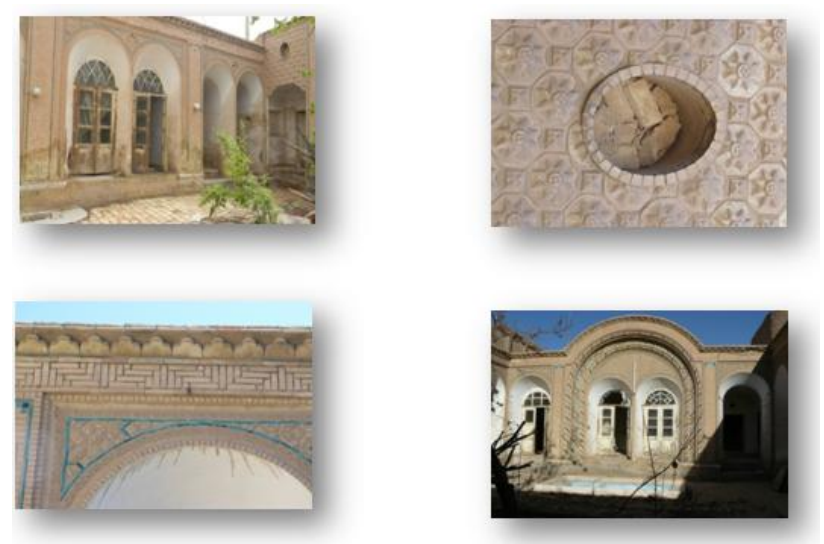

Figure 4. Module in the façade of Nikandish House

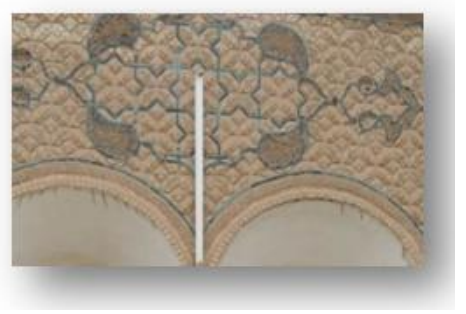

Figure 5. Using module in decoration and tiling
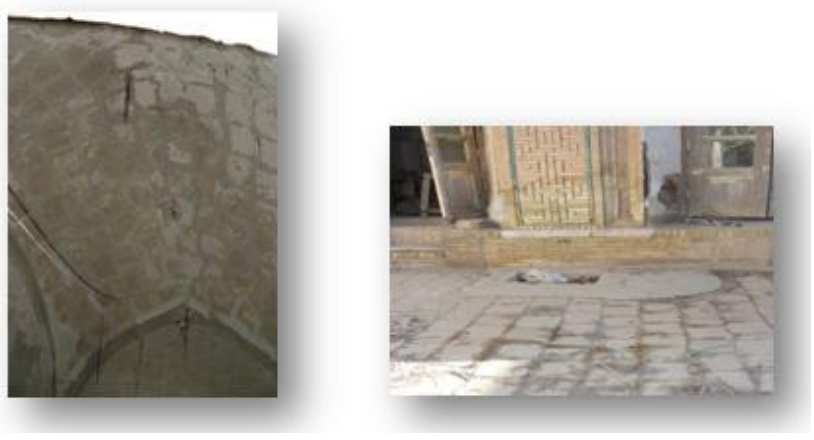

Figure 6. Using $25 \times 25 \mathrm{~cm}$ bricks in yard tiling and roofs

\section{Conclusion}

One of the solutions for the dilemma of housing construction in modern societies is constructing affordable houses. Inexpensive houses for low-income people in order to fulfill one of the most essential problems of this group and at the same time increase their level of residential satisfaction and living.

Investigating the details of Persian traditional houses, it becomes known that all the characteristics of these houses were based on the needs of the inhabitants, their culture and beliefs. Financially these houses have been affordable and people could own one depending their financial ability.

Nowadays the architecture of the houses has got distance from the true architecture and in some cases has made the inhabitants unhappy. If architects use the traditional Persian houses, they could have designs matching with the climate, keeping the confines, modular design, use of local material and flexibility, while try to have a modern combination to provide inhabitants' satisfaction and help solve the problem of housing crisis to some extent. 


\section{References}

[1] Eghbali, R. Hesari, p. Modular and prefabricated approach to flexible housing, Housing and rural environment journal, 143: 53-68, 1392.

[2] Khodaei, Z. Mireh, M. A review of global experiences in providing housing for low- income groups, 1-17, 1390.

[3] Rezaei, M R. Kamaei zadeh, Y. Assesssment of satisfaction of residents from Mehr housing complex Case study: Fatemieh Mehr site, city: Yazd. Quarterly journal of urban studies, 5: 13-25, 1391.

[4] Amini, S. Mehrbakhsh, S. Abdolkarimi, B. Moradi, S. An analyze the quality of housing with a satisfactory approach to cheap housing. First special conference on architecture and urban development, Iran, Shiraz, 1394.

[5] Medadi herris, S. Debate on affordable housing, first conference on Geographical sciences of Iran, 231-237, 1393.

[6] Ahmadi, V. The mechanism of low income housing and the finacing of achievable houses, 115-138, 1391.

[7] Liu A M M. Residential satisfaction in housing estates a Hong Kong perespectiv.Automation in Construction; 4: 511-524, 1999.
[8] Lampouniani V M, Architecture and urbanism in twentieth century, translator: Eetezadi L, Shahid Beheshti Tehran university publisher, 1994

[9] Salfarina A, Nor Malina M, Azrina H. Trends, Problems and needs of urban housing in Malaysia. International Journal of Human and Social Siences; 5: 977-981, 2010.

[10] Abdul Mohit M, Ibrahim M, Rashid YR. Assessment of residential satisfaction in newly designed public low-cost housing in Kuala Lumpur, Malaysia. Journal of Habitat International; 34: 18-27, 2010.

[11] Grdon Show J. Transit, Density and residential satisfaction. A dissertation submitted in partial satisfaction of the Requirement for the Degree of Doctor of Philosophy in City and Regional Planning in the Graduate Division of the University of California at Berkly. http://www. uctc.net.research/diss 028, 15-43, 1994.

[12] Ghiyaei, M H. Azimi, Sh. Shahabian, P. Measurment of the ratio of satisfaction with residential variables, neighborhood unite, Identity City, 47-58, 1392.

[13] Einifar, A R. A template for flexibility analysis in traditional Iranian housing, Fine arts journal, 13: 64-77, 1382

[14] Pirnia, M K. Acquaitance with Islamic architecture of Iran, Tehran Soroush Danesh publisher, 1388. 